\title{
Erratum to: MDCT findings after hepatic chemoembolization with DC-beads: What the radiologist needs to know
}

Juan Carlos Spina, Marina Ulla, Ezequiel Levy Yeyati, Mariana Cecilia Kucharczyk, Hernan Irusta, Jesica Lorena Savluk, Ricardo García-Mónaco

Department of Radiology, Hospital Italiano, Universidad de Buenos Aires, Gascón 450, Buenos Aires, Argentina

\section{Erratum to: Abdom Imaging}

\section{DOI 10.1007/s00261-012-9963-6}

In the article text reference 16 (Yu JS, et al) was numbered incorrectly. It should have been numbered as reference 15 .

Further, in the article text reference 15 (Novick SL, et al) was numbered and cited incorrectly. It should have been numbered as 16 and cited correctly as:

16. Guiu B, Deschamps F, Aho S, Munck F, et al. (2012) Liver/biliary injuries following chemoembolisation of endocrine tumours and hepatocellular carcinoma: Lipiodol vs. drug-eluting beads. J Hepatol 56(3):609-617

The online version of the original article can be found under doi:10.1007/s00261-012-9963-6.

Correspondence to: Marina Ulla; email: marina.ulla@hospitalitaliano. org.ar 